\title{
Los esposos William y Emma Hamilton en el imaginario occidental. El aporte de Susan Sontag con su novela El amante del volcán ${ }^{1}$
}

\section{The Hamilton Spouses in the Western Imaginary. Susan Sontag's Contribution with her Novel El amante del volcán}

\author{
Olaya Sanfuentes \\ Pontificia Universidad Católica de Chile \\ osanfuen@uc.cl
}

\section{Resumen}

Los esposos Hamilton son personajes históricos europeos famosos en su época, y cuyos nombres pasaron a la posteridad. Emma Hamilton por haber salido de la extrema pobreza y ascendido socialmente a través de sus habilidades y ambición, y por haber sido esposa de William Hamilton — coleccionista de renombre- y amante de Horacio Nelson. Este artículo aborda la construcción histórica de estos personajes a través de prensa de la época y bibliografía posterior, con un especial énfasis en el aporte de Susan Sontag en la configuración de los personajes y su época a través de la novela El amante del volcán.

Palabras clave: William Hamilton. Emma Hamilton, Susan Sontag, coleccionismo, siglo XviII.

\section{Abstract}

The Hamilton spouses were historical European characters who were famous during their time and their names passed on to posterity. Emma Hamilton for being a woman who challenged poverty and ascended socially because of her personal charm and ambition, and for being sir William Hamilton's wife - an important collector - and Horacio Nelson's lover. This article aims to shed light upon the historical construction of both characters using the press of the time and later bibliography, emphasizing Susan Sontag's contribution in the shaping of the characters and their epoch through her novel El amante del volcán.

Keywords: William Hamilton, Emma Hamilton, Susan Sontag, collections, eighteenth century.

1 Este estudio forma parte del proyecto "FAILURE: Reversing the Genealogies of Unsuccess, $16^{\text {th }}-19^{\text {th }}$ Centuries" (H2020-MSCA-RISE, Grant agreement: 823998] dentro de las líneas de trabajo establecidas en el WP2 "Biography and the Individual. Strategy, Choice, Self-representation, Performativity". 


\section{Introducción}

William y Emma Hamilton fueron personas y personajes de la cultura occidental que continúan vivos en la memoria a través de diversos soportes y legados; en esta trayectoria, el libro El amante del volcán de Susan Sontag es, probablemente, de los últimos intentos en esta historia de construcciones y reconstrucciones de sus figuras que comienza en el siglo XVIII —época en que los personajes históricos vivieron- $y$ que todavía llama nuestra atención e interés. ${ }^{2}$

Tal como sugiriera Peter Burke para su gran obra La fabricación de Luis XIV, y guardando las proporciones entre los personajes estudiados, por una parte, y el historiador a cargo del ejercicio, es importante distinguir las representaciones contemporáneas de los personajes en cuestión, de las representaciones posteriores de los mismos. Y debemos estar atentos a los cambios de imagen en el tiempo y las diferencias de opinión entre los diversos productores y receptores de estas imágenes. Como apuntara Burke, cada representación —en este caso de nuestro William Hamilton y de su esposa Emma - hay que verla como una representación de la persona y de su entorno, así como un evento cultural en sí mismo.

Cuando uno busca en internet El amante del volcán, los resúmenes y las reseñas literarias de la novela relatan el argumento de esta historia de amor situada en Nápoles en el siglo XVIII, que termina siendo un trío amoroso entre sir William Hamilton, lady Emma Hamilton y el almirante Horacio Nelson (en la novela de Sontag: "El Cavaliere”, la esposa del "Cavaliere" y el héroe). Los dos últimos terminan viviendo libremente un amor adúltero y Hamilton pasa a la historia como un gran cornudo. En la figura 1 se ilustra la relación entre Emma Hamilton y Nelson, mientras William Hamilton escudriña escondido entre unas antigüedades egipcias.

Este resumen burdo pero elocuente contiene mucha verdad con todas las posibles reacciones asociadas a este escándalo, pero también esconde muchas sutilezas y contextos más sofisticados que los historiadores pueden sondear y proponer para una lectura más rica y poliédrica de los personajes. Están, entonces, la fabricación y reacción contemporánea de una imagen de los esposos Hamilton; luego otras representaciones y recepciones posteriores como podrían ser la obra Pygmalion de Shaw, la película That Hamilton Woman de Alexander Korda y algunos artículos científicos que intentan rescatar el aporte de William al gusto de la época, así como al Museo Británico y a la geología. También hay artículos científicos dedicados a Emma, esta vez para analizar sus Actitudes, género artístico teatral que habría sido inventado por ella. Por último, tenemos la obra de Susan Sontag que, si bien no es una novela maestra, sí constituye un último eslabón en el proceso constitutivo de estos perso-

2 Es imperante agregar que posterior a la novela de Sontag vio la luz la obra de la historiadora británica Kate Williams titulada England's Mistress. Este libro fue nombrado el libro del año por el Times y el Independent (2005-2006). En este artículo se usará la edición de Arrow Books, Random House, Londres, de 2007. 


\section{FIGURA 1}

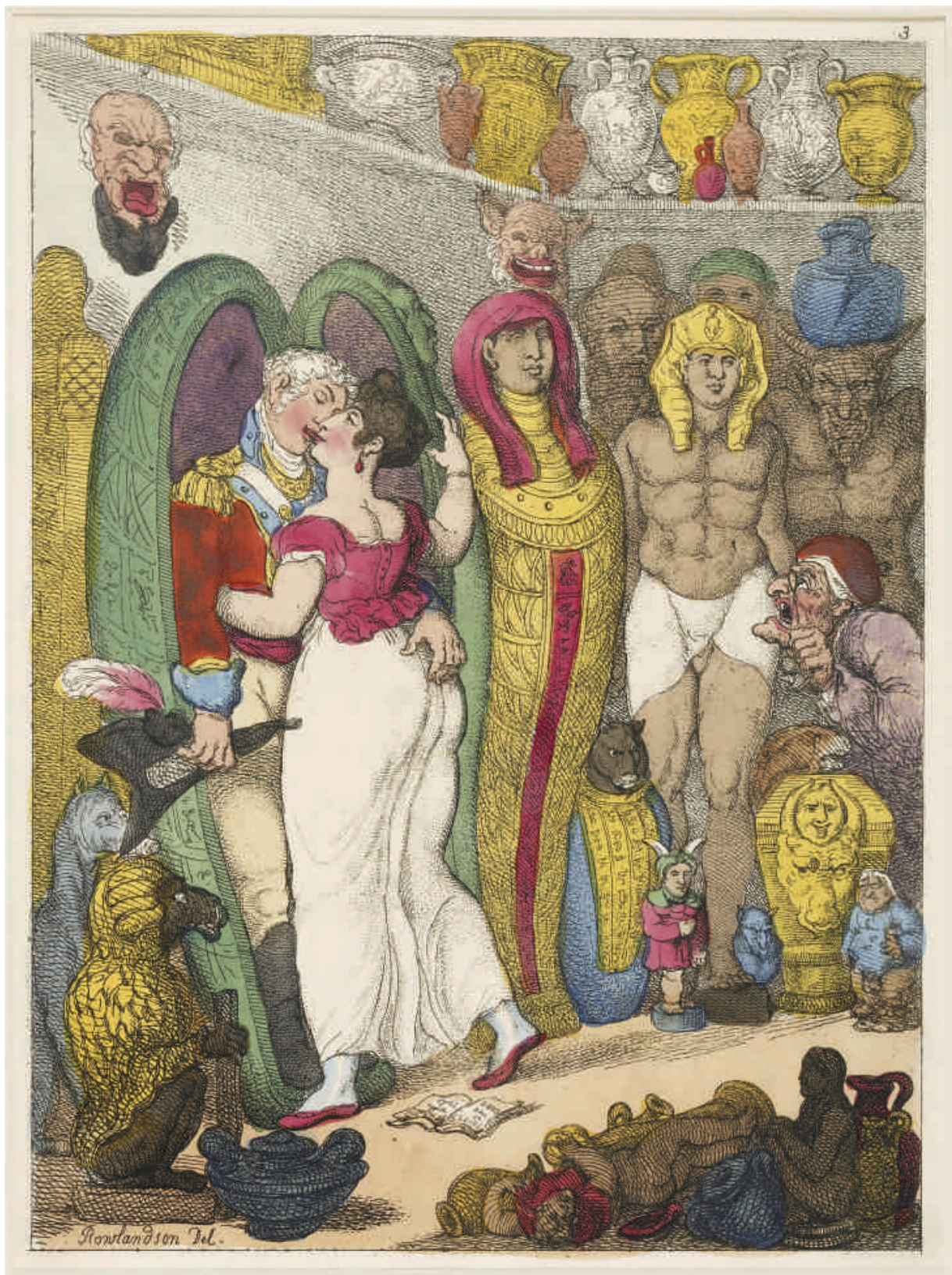

Grabado coloreado a mano, $33.3 \times 24.8 \mathrm{~cm}$. Publicado por Thomas Tegg. British Museum. Fuente: Modern Antiques, 1811 (?), impresión por Thomas Rowlandson. (๑) The Trustees of the British Museum. 
najes. Y más aún, contiene una puesta en escena contextual sofisticada, informada e históricamente documentada para que, entre líneas, se lea que William Hamilton no fue la única víctima de esta historia. Luchadora acérrima a favor de los derechos de las mujeres, su novela no elimina la importancia del contexto en la explicación de ciertos fenómenos, pero sí es crítica frente a cualquier individuo o sociedad que trate a las mujeres como objetos.

Por otra parte, la novela de Sontag también entrega claves para entender los aportes de sendos personajes a la historia de la cultura en general y del arte en particular, permitiéndonos salir de la historia de amor propiamente tal.

\section{Imagen de William y Emma en su época}

\section{Emma Hamilton. Su biografía y lo que de ella se dice cuando muere}

A través de fuentes de época y de bibliografía se puede reconstituir la biografía de Emma Hamilton. Es el caso de una mujer que por su clase y su pobreza estaba destinada a una vida de anonimato y pesares. No obstante, logró sobrepasar sus condiciones y destino, asomarse en los anales de la historia y ser considerada en su época como una "mujer que jugó un magnífico papel en el teatro mundial" (Boston Weekly Magazine 98-982); su fama contemporánea trascendió a su muerte llegando hasta el día de hoy. Se convirtió en un personaje público, lo que explica que muchos sintieron la necesidad de dar su opinión frente a esa vida tan extraordinaria. Estas manifestaciones generaron verdaderos grupos de opinión entre los que la despreciaban por su arribismo, falta de moral y por haber pervertido al máximo héroe de la historia de Inglaterra. En periódicos norteamericanos, incluso, se le describía como una destructora de hogares felices, la ruina de los que estaban a su lado, la abusadora de la confianza de su marido, la vengadora de los que no se colocaban a sus pies, la instigadora de intrigas y la causa de crueldades (Boston Olive Branch 4-40). En el lado contrario se encontraban los que admiraban su capacidad de desafiar el destino, convertirse en una mujer famosa por su belleza y sus aptitudes artísticas y desafiar el rol tradicional de la mujer. Los que han visto en lady Hamilton un personaje laudable, se proyectan hasta el día de hoy a través de una sociedad que lleva el nombre de Emma Hamilton y se dedica a enaltecer su figura. La película That Hamilton Woman, con Vivian Leigh y sir Lawrence Olivier, si bien no es una apología a Emma, sí muestra a una mujer graciosa, llena de energía y de una actitud tan naïve que la redime de cualquier culpa. Esa película fue estrenada el año 1941 y era la favorita de Winston Churchill. ${ }^{3} \mathrm{Su}$ contexto es el de una Inglaterra que necesitaba aliento para enfrentar la guerra y lo

3 En el museo de Londres dedicado a Winston Churchill hay una vitrina donde se recrea su vida cotidiana. Ahí, se reproduce esta película. 
hace a través de una pieza azucarada (Olster 117-139). En años más recientes, una exposición en el National Maritime Museum desafió la tendencia generalizada de relacionar esa institución con Horacio Nelson y desplegó una exposición dedicada a Emma Hamilton con un texto donde los colaboradores enfatizaban su deseo de mejoramiento personal, educación y respetabilidad (Colville y Williams 7). El texto es enfático al declarar que pocas figuras históricas han sido reflejadas - tanto en su época como con posterioridad - por espejos tan diferentes: el de los artistas, el de las habladurías, los biógrafos, los historiadores y ella misma (11).

Para sondear en la opinión pública la imagen de Emma tras su muerte, las fuentes que existen son, principalmente, un libro anónimo que relata su biografía y la publicación de las cartas que se escribió con el almirante Nelson y las reacciones contemporáneas frente a la publicación de esas cartas. Respecto al libro anónimo con sus memorias, la prensa opinaba: hay quienes aprovecharon el evento de la publicación para decir que ella fue una mujer extraordinaria y que su vida más parecía de ficción que de verdad. Según el Monthly Review su vida fue tan compleja, que se necesita que quien la relate sea fiel a la verdad, el decoro y la moral (295-2958). A este diario le parecía que el autor de esas memorias conocía los hechos y que estaba preocupado de la verdad más que de halagar, de mostrar con esa vida más una advertencia que un modelo. Se lee la importancia que se le otorgaba a la belleza en la época, pero los peligros que estaban detrás de la belleza sin virtud. Otra prensa - a ambos lados del Atlántico- estaba en desacuerdo con las buenas intenciones del autor: Blackwoods Edinburgh dice que estas memorias estarían basadas en malas intenciones y en rumores (417-41713) y el Boston Weekly Magazine deseaba que nadie leyera esas memorias pensando en Emma Hamilton como un modelo a seguir (98-982).

Tras la muerte de Nelson, se publicaron también las cartas que se escribiera con Emma. En el Quarterly Review de Londres, del año 1814, el editor se lamenta de tener que compartir con sus lectores el libro en que se publicaron las cartas de Emma Hamilton y lord Nelson, ya que la única cosa que habría nublado la brillante fama de Nelson fue su vida en Nápoles (Quarterly Review, 73-735). ${ }^{4}$ Nada justificaba, para esta revista, que se hubieran publicado aquellas cartas. A Nelson se le perdonaban sus pequeñas debilidades por todo lo que hizo por su patria. Continúa el artículo diciendo que quizás lo único que alimentó estas cartas fue la vanidad de la señora Hamilton. En alguno de sus obituarios se dijo que por necesidad es que, probablemente, Emma habría hecho llegar estas groseras cartas al editor que las publicó (Boston Olive Branch 4-40; Edinburgh Review 398-39813).

Para otras publicaciones (Monthly Review), la relación de Emma Hamilton con Nelson fue vergonzosa. Fue Emma la que provocó la separación de Nelson con su

4 "It is with great regret that we undertake to give our readers some accounts of these volumes. The only cloud which has obscured the bright fame of the immortal Nelson was generated in the fatal atmosphere of Naples" (Quarterly Review 73-735). 
esposa. Además, se habría entrometido en política y habría generado muchas intrigas (Analectic Magazine 153-1534); entre otras, el haber influido en la muerte del príncipe Caraccioli.

El Edinburgh Review del año dice que no recuerda haber visto una publicación más reprochable y en que fuese más elocuente el móvil de sacar provecho de la debilidad de los muertos. No es que las cartas no fuesen genuinas, pero cuál era el afán de publicarlas sabiendo que causaban gran dolor a muchas personas que las leían.

También están los artículos que se escribieron tras la muerte de Emma, que asimismo muestran las diferentes opiniones frente a este personaje. Cada publicación que se refiere a ella no puede dejar de relatar toda su historia y dar su opinión al respecto. Muchas de estas fuentes, al hacer el recuento de su vida, se refieren en tono de crítica implícita al tratamiento que tuvo Emma de parte de ciertos representantes de la élite británica masculina de la época que la rescataban de su situación. Luego de haber pasado por varios hombres que la protegieron de la pobreza y aprovecharon su belleza y encanto, Emma llegó donde Charles Greville, un caballero y connoisseur que apreciaba la estética y que, según crónicas de comienzos del XIx (Rural Repository 43-434), se apoderó de Emma como si fuera un vaso griego. La fuente es sarcástica al decir que Greville fue muy humano porque la educó. Ella respondió muy bien porque hizo rápidos y considerables progresos en todo lo que estudiaba y especialmente en la música, ya que desarrolló una voz que realmente derretía los corazones. En su obituario, sin saber qué nombre ponerle a la relación entre ella y Charles, decían entre comillas que fue su "protector" (Euterpeiad 110). Otros claramente criticaron a este caballero diciendo que trató a Emma como un juguete que dejó de ser valioso para él (Boston Olive Branch 4-40). Habría tenido tres hijos con Charles - otras fuentes lo desmienten-, evidenciando lo que se decía en la opinión pública de entonces respecto de ella: su vida era más de fábula que de verdad.

Al verse envuelto en deudas, Greville recurrió a su tío William Hamilton, con quien tenía afinidad en su obsesión por la belleza, las antigüedades clásicas y el coleccionismo; y le vendió a Emma a cambio de que el tío pagara sus deudas o lo nombrara su heredero.

A cargo de lord Hamilton, Emma siguió aprendiendo muchas otras habilidades y llegó a convertirse en su esposa - lady Hamilton - y luego en íntima amiga de la reina Carolina de Nápoles. Según algunas fuentes que explican en forma irónica su desarrollo, en el calor y el suelo disoluto de Nápoles, Emma pudo estar a sus anchas y desarrollar su voluptuosidad y sus dotes. Era una belleza sin escrúpulos, pero que bajo la tutela de Hamilton llegó a rivalizar con las mejores cantantes de la época. Tenía grandes aptitudes performativas, con un chal se convertía en todos los personajes que quisiera o le pidieran (Spirit of the Times 448).

Cuando conoció a Horacio Nelson, se constató que el romance fue una bomba y algunos dijeron que cuando conoció el poder se convirtió en una mujer cruel y que llevó a Horacio Nelson a una vida de vicio (Boston Weekly Magazine 98-982). 
Se dice que la hija que habría tenido Emma y a quien bautizó como Horacia era hija del almirante.

Cuando Hamilton murió, Emma se fue a vivir con su galán. William dejó su herencia a su sobrino Charles, por resentimiento hacia la conducta que tuvo Emma con Nelson; cuando luego Nelson murió, Emma se quedó sola, enferma, pobre y alcohólica. Ya convertida en un objeto de repulsión universal murió en Calais (Boston Weekly Magazine 98-982). Según alguna prensa, la nación inglesa se comportó de forma muy cruel y desgraciada con esta mujer. Esta misma fuente piensa que el libro anónimo que salió tras su muerte es totalmente infame (Notes \& Queries 343-3432). Que era una mujer totalmente generosa y que cuando se murieron tanto Hamilton como Nelson la gente fue muy cruel e ingrata con ella. Incluso se llega a decir que la intimidad de Emma con Nelson fue un enigma y que más bien se trataba de un amor platónico. La revista de mujeres Ladies Monthly Museum aprovechó la muerte de Emma para advertir a sus mujeres que la belleza sin virtud no era aceptada socialmente (246-2465). Relataba las bondades que tuvo lady Hamilton y hablaba de sus Actitudes, las que merecieron incluso un libro de Rehberg con grabados de Puoli. Esta publicación no quiso entrar en los detalles de la relación entre Emma y Nelson, que se habría prostituido a través de la prensa. Esto, decía la publicación, habría que olvidarlo y mejor recordar que Emma tuvo un entierro cristiano en el cementerio de Calais en 1815. En uno de los obituarios de lady Hamilton se señalaba que la que fue antes tan aclamada, murió en pobreza y exilio. Junto con contar de sus orígenes el documento decía que fue una de esas mujeres que desde muy temprano experimentó las vicisitudes de aquellas mujeres cuya belleza les lleva al vicio y que dependen de ella para poder subsistir. De su relación con Nelson se habla de una "amistad", entre comillas, que habría dejado poco crédito en ambos (Analectic Magazine 175-1752).

También sabemos de Emma a través de fuentes visuales. El pintor Romney la retrató tantas veces que podemos deducir una suerte de obsesión o fetichismo de su parte. De estos retratos se ha dicho que capturan una sensualidad que no se ve en los retratos de personas de sociedad de esa época (Colville y Williams 91). Emma volvía a aparecer como una suerte de objeto bello que había que reproducir. Fue con Romney y sus cuadros que la vida de fama de Emma comenzó, pero no se puede dar por cierto el rumor de que la relación de Emma con el pintor era de sirviente, modelo y amante. El la llamaba la divine lady y su adoración lo llevó a pintar unos 23 cuadros de ella.

Emma fue también retratada por Angelica Kauffman y Elisabeth Vigée, George Romney, sir Joshua Reynolds, Benjamin West, John Raphael Smith, Gavin Hamilton, Friedrich Rehberg, Louise-Elisabeth Vigée-Lebrun, Dominique Vivant Denon, Constantina Coltellini, Henry Fuseli, Thomas Lawrence, Jean Baptiste Monnoyer, Wilhelm Tischbein, Angelica Kauffmann y James Masquerier (Olster 117-139) y sus Actitudes fueron inmortalizadas en los doce grabados que Hamilton encargó a Friedrich Rehberg y que se inspiran en las poses de Emma surgidas de los vasos de William. 


\section{Emma como "objeto" de estudios científicos}

Con los años, el caso de Emma ha dado pie para algunos estudios científicos que desarrollan dos aspectos de su vida que considero importantes para tener una idea cabal del personaje. Uno de esos aspectos es su relación con la obra Pygmalion de Shaw y el otro es el desarrollo de un supuesto género artístico por ella inventado y que devino llamarse Actitudes.

Eliza Doolittle - la heroína de Pygmalion - tiene muchas cosas en común con Emma Hamilton: es cálida, una joven adorable y socialmente poco adecuada, además de mostrar errores gramaticales y de pronunciación cuando habla. Si bien se han reconocido varias fuentes de influencia en la obra de Shaw, no se puede negar la importancia del tópico de la relación maestro y pupila coincidentes en ambas circunstancias. ${ }^{5}$ Y, si bien Charles Greville no descubrió a Emma vendiendo flores en Covent Garden, de muchas formas su ascenso de las profundidades de la sociedad se parece a la de Eliza Doolittle (Hellman 218). Greville le pedía a Emma que no volviera a ver a los amigos que frecuentaba antes y que siguiera las instrucciones que le daba, igual como Eliza debía hacerlo con Henry Higgins. Emma debía convertirse en una mujer nueva y comportarse en forma decorosa y elegante.

Respecto al género de las Actitudes, eran estas una representación performática realizada por muchachas para representar mujeres y poses de la Antigüedad clásica. La inspiración provenía de objetos, por lo que aquellas que las realizaban podían describirse como "estatuas vivientes". Los cuerpos de estas mujeres se tornaban en centro de un discurso cultural que proporcionaba prestigio (Rauser 465), pero era un prestigio que hablaba de su dueño o de su benefactor como un hombre que perseguía la virtud a través del artificio. En el caso de Emma, ella representaba a las mujeres de los vasos de William o se inspiraba en las pinturas murales de las recién excavadas ciudades de Pompeya y Herculano complementando, entonces, a través de su cuerpo y su arte, la oferta turística del Nápoles del siglo xviII. No usaba más que un chal, y a través de gestos y posturas se podía convertir en Efigenia, Medea, Diana o Juno. Pasaba muy rápidamente de una escena a otra de la historia, poniendo énfasis en las emociones y pasiones de sus personajes, lo que calaba fuertemente en el estado de ánimo de la audiencia. Estas actitudes fueron recogidas por las artes visuales, pero también por las descripciones de los viajeros que llegaron a Nápoles en el siglo XVIII, siendo Goethe el que articularía la recepción alemana de este género. Pareciera que él no vio a Emma personalmente, pero se informó por otros testigos y presenció a otras actrices que las desarrollaron después (Maierhofer 226).

5 Esta clásica historia pasaría luego al cine con el nombre de My Fair Lady (1964), interpretada por Audrey Hepburn y Rex Harrison. Recibió ocho premios Óscar. 


\section{Lord William Hamilton}

Existen fuentes para conocer las actividades políticas, científicas y artísticas de las cuales formó parte lord William Hamilton. Hay publicaciones que tratan todas sus facetas, comenzando con su desempeño como embajador británico en Nápoles (Constantine 19). Desde su villa en esta ciudad italiana del sur Hamilton avistaba diariamente el volcán Vesubio y escribía cartas de registro a la Royal Society de Londres. Durante la época en que le tocó vivir en Nápoles, el Vesubio estuvo más activo que en la época de Plinio. Consciente de que él no era un experto, dejaba, no obstante, observaciones minuciosas y con importantes detalles que fueron de suma utilidad para las conclusiones geológicas y vulcanológicas de la época. En su correspondencia dejó evidencia de la importancia de la experimentación y el de ser testigo de un evento geológico de esa envergadura. El año 1766 le escribió una carta al presidente de la Royal Society relatándole la última erupción y hablándole de su método: llevaba dos años mirando los cambios que experimentaba el volcán y le llamaba la atención que tiraba más humo cuando había mal tiempo, ocasión en que también se escuchaban explosiones desde Nápoles, que está bastante lejos del Vesubio. Mientras escribía la carta, el humo se había puesto ya bastante negro y comentaba que justo antes de la erupción vio la misma figura que habría visto Plinio el Joven en su época: un humo en forma de pino.

Se hizo famoso por sus excursiones al cráter del volcán, del cual se sentía su guardián. Cuando estaba arriba, recolectaba todo tipo de minerales, piedras y lava. Su pasión por el volcán también se encarnó en un libro de dos volúmenes -Observations on the volcanoes of the Two Sicilies-, publicado en 1776. Todas las anotaciones son de William Hamilton y muestran su comprensión de la naturaleza como un sistema en que cada componente, vivo o muerto, natural o artificial, tiene un rol. Sus anotaciones y sus cartas a la Royal Society deben de haber constituido un aporte en su época porque se ha dicho de él que sus estudios de geología constituyeron más que un hobby, ya que sus métodos no tuvieron nada de amateur. Era muy riguroso en sus observaciones y las compartía cuando sentía que tenía suficiente evidencia. Solo entonces establecía una línea de pensamiento que le llevaba a una hipótesis (Sleep 322).

De su actividad de coleccionista sabemos por diversas fuentes: las cartas que escribió al Club de Diletantes, las ventas que hiciera al Museo Británico, los catálogos que comisionó de sus vasos griegos, romanos y etruscos. Esta colección y su publicación constituyeron un verdadero aporte al conocimiento, al tiempo que afectaron la opinión y el gusto de la época (Constantine 21), básicamente por la publicación Vases and Volcanoes, tras la exhibición que se hiciera en el Museo Británico en 1996, así como muchos otros artículos científicos que se han escrito sobre sus colecciones y sobre su aporte al desarrollo del gusto clásico en Gran Bretaña.

También hay fuentes visuales que nos proporcionan información de Hamilton. Le gustaba retratarse con el volcán en el fondo de la composición. En el retrato famoso que le hiciera Reynolds el año 1777, el volcán aparece como uno de los atributos del 
"Cavaliere", así como los vasos griegos que lo hicieron famoso. Volcán y antigüedades griegas, naturaleza y arte, dos elementos que a él le gustaba ver y analizar en forma conjunta. O como bien resume David Nolta respecto a lo que hacía Hamilton con todo lo que le rodeaba: estudiar, adquirir y publicar (112).

\section{Los personajes de William y Emma en la novela de Sontag}

Susan Sontag debe haber leído todas y cada una de las fuentes que he mencionado hasta ahora, exceptuando la bibliografía científica que apareció después de la publicación de su libro. Sontag muestra en su novela con quién y por qué escribía cartas el "Cavaliere". Susan Sontag dijo sentirse muy satisfecha con esta novela, probablemente porque era una ávida lectora, recolectora de historias e investigadora de aspectos de la cultura universal y del canon. Y todo este conjunto de elementos culturales que a ella le interesaron y que buscó con apetito omnívoro están presentes en esta novela: el gusto por el arte, las disquisiciones sobre la belleza y el mundo de los clásicos y su reproducción, el rol de la mujer, el coleccionismo.

A sir William lo constituye como un inglés cultivado de la época, preocupado por cuestiones científicas, de arte, del gusto, un anticuario. En el libro se describen sus idas al volcán para poder ver in situ los derramamientos de lava, los que también se sabe habría presenciado desde su villa. No se mencionan en la novela los encargos que hiciera a un lugareño de dibujar diariamente los movimientos del volcán, pero Sontag logra muy bien proyectar tanto la pasión que siente lord William por la vulcanología en general y el Vesubio en particular, como la utilidad de los avistamientos que hiciera Hamilton que luego reportaba en cartas a la Royal Society de Londres. Si bien siempre está citando la obra de Plinio para comparar sus propios avistamientos con los que describiera el romano siglos anteriores, la escritora deja muy claro el valor de la experiencia y la experimentación en la adquisición de los conocimientos del siglo XviII. Por eso es que Sontag relata que desde la Royal Society de Londres lo felicitan por sus osadas expediciones que permitieron observaciones a corta distancia. Sontag tiene que haber leído las cartas que escribiera Hamilton a sus pares en la Royal Society porque incluso recurre a las mismas figuras literarias que utilizara entonces Hamilton. Este habla sobre que del volcán saltaban showers of stones en una de las erupciones, misma figura que utiliza Sontag en su novela.

Para William todo lo que está a su alrededor y con lo que se relaciona son objetos a los que tiene más o menos afecto. Los animales y las mujeres de su vida no son una excepción a esto. Tendría un mono que le servía para entretenerse, para experimentar con él, incluso para desarrollar unas ideas evolucionistas, pero del que se aburrió prontamente. Con Catherine - su primera esposa - se casa por su dinero, relata en la novela Sontag, a pesar de que luego se acostumbra a su presencia - como quien se acostumbra a un sofá- y le enfurece el hecho de que ella al morir lo abandone. Cuando 
se muere Catherine, él mismo se impresiona de que lo afecte. Siente melancolía, poco vigor, se le va el entusiasmo. Y entonces Sontag describe el perfil del melancólico. No hay sentimientos de empatía ni dolor por ella. Sontag nos lo pinta como uno que utiliza a las personas según si le sirven para sus intereses. Con el dinero de Catherine puede continuar con su carrera política y sus compras de antigüedades.

A Emma la recibirá como un objeto o como el reflejo de la belleza emanada de un objeto. Cuando le manda a Emma, Charles, su sobrino, básicamente le dice que podía hacer con ella lo que quisiera y que podía garantizar que el material era bueno. Con el tiempo, esta se convertiría en su nueva pasión. Comienza describiendo su belleza en relación con los objetos bellos que ya conoce: "La suya era la belleza que había adorado sobre tela, como estatua, en el costado de un jarrón. Ella era la Venus con las flechas, ella era la Tetis reclinada esperando a su desposado. Nada le había parecido nunca tan bello como ciertos objetos e imágenes: el reflejo, no, la evocación de una belleza que nunca existía en realidad o que ya no existía" (Sontag 179). Emma podía tener valor si su belleza se relacionaba con la que emanaba de los objetos preciados. O si era capaz de encarnar esa antigüedad que tanto fascinaba al "Cavaliere".

Y es que, como dice Sontag, los coleccionistas pueden llegar a querer a los objetos más que a las personas, porque confían más en los artefactos. Los objetos no te defraudan. El mismo puede ser mejor descrito a través de sus propios objetos o, como dice Sontag, las paredes de su casa hablan más de su vida interior que ninguna otra fuente.

Sontag es una verdadera maestra en contar historias de sujetos a partir de objetos, logrando con sus disquisiciones adelantarse a las que hicieran los estudios interdisciplinarios sobre la cultura material. Aunque también se ha dicho que Sontag es una adelantada a las reflexiones de otros especialistas en lo que se refiere a la importancia de la imagen y su reproducción, al referirse a Emma como una idea que está en las mentes de los europeos del siglo XviII. Quizás en esta estrategia es donde percibo su mayor fuerza y aporte a través de esta novela en el proceso de construcción de los Hamilton. Y es que al hablarnos de William y Emma a través de los objetos no solo está utilizando una estrategia narrativa, sino que está hablando con el tono y las preocupaciones de la época, de una clase social y cultural del siglo xviır que quiere mostrar su relación con una ciencia experimental, de una clase admiradora de la Antigüedad clásica y los artefactos en los que se manifiesta, de un grupo social preocupado de la belleza y sus diversas materializaciones y encarnaciones. Estas imágenes son primero un producto de la alta cultura, pero luego se van reproduciendo hasta convertirse en algo al que muchos pueden tener acceso. Esto se puede apreciar muy bien en las descripciones de las Actitudes performadas por Emma, quien experimenta con diversos personajes y posturas, desafiando los límites entre la naturaleza y el arte, entre la Antigüedad y la modernidad, entre la naturaleza y la cultura (Rauser 465). Es el caso también de lo que ocurriera con los vasos que el "Cavaliere” pone a disposición del público al entregarlos al Museo Británico y la reproducción iconográfica que esto tuvo. El jarrón Portland, por ejemplo, fue tomado por los fabricantes de loza Wedgwood y masificado, llegando 
a muchos hogares ingleses. La misma Emma habría sido reproducida visualmente varias veces para que su figura y su belleza pudieran ser accesibles a varias familias inglesas del siglo xviıI (Colville y Williams 92).

A través de su novela, Sontag muestra a los Hamilton como personajes de un escenario donde se discuten temas de cultura visual y de cultura material propios de la época. Los hombres de élite están preocupados de estos asuntos y configuran su identidad alardeando de sus colecciones, de sus adquisiciones, sean estas objetos, mujeres-objetos, animales-objetos, con los cuales aparecen en los espacios públicos y luego en las publicaciones que conforman la opinión pública de la sociedad de la época. Hacia 1786, un amigo de Hamilton llamado James Bayres le decía al obispo de Killala que el amigo en común se encontraba bien, ya que recién había adquirido una pieza moderna que lo cansaría más que cualquier volcán o antigüedad napolitana. Se refería a Emma. En una carta que le envía al botánico Banks, William le comentaba que una bonita planta llamada Emma había sido trasplantada desde Inglaterra a Nápoles y que no perdió su belleza. Incluso en artículos especializados posteriores se ha insinuado esta característica de William Hamilton, lo que nos permite decir que la investigación que hiciera Sontag para configurar a sus personajes es muy seria y minuciosa. En un artículo de David Nolta, este decía que Hamilton "approached both people and things as objects of virtue, and as such, obtainable and subject to resale" (108-114). Y líneas más delante Nolta habla de Emma como una adquisición más, junto con el paisaje del volcán y los vasos griegos. Lady Palmerstone, por su parte, decía que Hamilton la idolatraba y estaba tan orgulloso de tener tan valioso y precioso mármol solo para él (Rauser 470).

Los hombres de la época van también mostrando su identidad a través de sus opiniones estéticas. La belleza es un espectáculo, la belleza se emparenta con lo pintoresco: son un montón de cuadros que tienen que ver con un tipo de mirada. Las disquisiciones del "Cavaliere" respecto a la belleza muestran la importancia de mostrarla públicamente para decir algo de sí mismo: “¿Qué hacemos con la belleza? La admiramos, la ensalzamos, la mejoramos (o lo intentamos) para exhibirla; o para esconderla... ¿Qué es la belleza sin un coro, sin murmullo, suspiros, susurros?" (Sontag 183).

Como hombre de su época, arte y naturaleza no son distinguibles para Hamilton; están para placer del espectador y del que quiera poseerlas. Por esa razón es que su pasión por el volcán lo lleva a recoger y coleccionar pedazos de lava a medio enfriar, todo tipo de minerales y muestras de sales y sulfuros. Estas muestras las donó al Museo Británico y las mandó a sus expensas, nos relata Sontag. Todo conocimiento procede de los sentidos, relata Sontag para referirse a las disquisiciones experimentales del "Cavaliere" que, en este ámbito como en otros, es un hombre de su época. Colecciones de antigüedades y fragmentos de volcán, por esta integración entre arte y naturaleza, terminaron juntos en el Departamento de Natural and Artificial Productions del Museo Británico. Hasta entonces, no había muchas antigüedades, con la excepción de las que mandara sir Hans Sloane, que consistían, principalmente, en monedas y 
gemas, pero nada monumental (Jenkins y Sloan 192). Era la forma dieciochesca de mirar el mundo, que Sontag logra captar y compartir con sus lectores.

Sontag dedica varias páginas a lo largo de todo el libro a hacer disquisiciones respecto del coleccionismo. Y es que la metáfora del coleccionista es perfecta para ella, que se ve reflejada en el personaje de Hamilton. Su avidez, su imposibilidad de saciarse, la necesidad de poseerlo todo, de saberlo todo reflejan a la Sontag (Mendelsohn 39). Casi todo lo que Sontag dice de Hamilton podría aplicarse a ella misma (Jenkyns 46). Aunque al ser ella misma una coleccionista de historia, de aventuras, de anécdotas, de impresiones y de libros, desafía lo que ella misma describe para la época - a través de su novela - como una actividad de hombres (Sontag 37).

Emma Hamilton, por su parte, una muchacha mucho menor que Hamilton, y ya sabemos que de procedencia social y económica inferior, está dispuesta a aprender de todo para agradar a cualquiera que le proporcione seguridad y bienestar. Si bien Sontag la hace afectarse cuando se da cuenta de que los días y las semanas pasan y su amado Charles no vendrá a recogerla a Nápoles donde su tío, finalmente termina aceptando un destino que ella ya conocía: pasar de hombre en hombre. En la película That Hamilton Woman (1941), en cambio, el director Alexander Korda elige una conversación sincera entre un frío Hamilton y una ingenua Emma a quien se le revela que Charles es un mentiroso y que no es verdad que vendrá a recogerla. Ella llora desconsoladamente, pero luego se reinventa como la compañera de William. Según los que han estudiado la correspondencia de Emma, sus cartas tras el abandono de Charles muestran los sentimientos verdaderos que ella sentía hacia el joven y retratan a una mujer honesta, sagaz, poco ingenua y ansiosa por redimirse de un pasado poco honorable (Recca 337).

Emma es una belleza que debe ser exhibida. Uno de los cuadros que hiciera Romney de Emma tuvo que se reproducido por la técnica de grabado para que más persona pudieran admirar su belleza. Emma Hamilton en Nápoles cantaba para el "Cavaliere" y sus amigos, representaba sus Actitudes y según Sontag incluso subiría al volcán. Y él asiente cuando ella actúa, en una suerte de permanente examen frente a su protector.

Sontag también muestra la vocación de Pygmalion que tiene William al querer pulir a Emma, tal como comenzara a hacerlo Charles cuando era de su posesión. Al igual que Eliza Doolittle que habla mal, la Emma Hamilton de Susan Sontag escribe mal sus cartas. Sontag pone entre los pensamientos del "Cavaliere" el que la belleza hay que enseñar a exhibirla y para eso Emma debe pulirse. Le toma profesores desde la mañana a la noche; profesor de canto, de dibujo, de italiano, francés y de piano. Luego también recibió clases de botánica y geología. Leía manuales de autocontrol para mujeres y libros de poesía. Para el "Cavaliere" se estaba convirtiendo en una atracción internacional, como el volcán (Sontag 188).

En las últimas páginas de su novela, Sontag recure a otros narradores para poder complementar la imagen tanto de William como de Emma Hamilton. Para eso hace 
hablar a Catherine, a la misma Emma, a su madre y a un personaje que solo aparece al final de la historia.

Sontag ha escrito una novela que termina de configurar la imagen de Emma y William Hamilton en el imaginario. Lo hace, de alguna forma, redimiendo a Emma a través de una descripción de época en que la sobreponderación que tienen la belleza, la acumulación y colección de objetos, y la experimentación como forma de entender y apropiarse de la realidad, constituyen el contexto que convierten a Emma en una víctima de los hombres. Cuando los años pasan y Emma engorda y envejece, comienza a engalanarse en exceso, precisamente para decir, continúa Sontag: "No me miréis a mí, mirad mis vestidos de satén, mis anillos, mi cinturón con borlas, mi sombrero con plumas de avestruz". Y es que Emma, como otras mujeres que se movían entre la burguesía europea del siglo XviII debía ser un objeto estético sujeto a un juicio estético. La mirada puesta sobre ella era fetichista y sujeta a objetivación y control visual (Bermingham 7).

Tras esta descripción de los personajes, ¿debemos entristecernos frente a la suerte de sir William o más bien tenemos que estar aliviados de que con Nelson y según Sontag, Emma dejara de ser un objeto?

\section{Referencias}

"Art. V. The Letters of Lord Nelson to Lady Hamilton, with a Supplement of Interesting Letters", Quarterly Review, 1 Abr 1814, pp. 73-735. Revisado en: http:// search.ebscohost.com/login.aspx?direct $=$ true $\& d b=h 9 h \& A N=37697827 \&$ site =eds- live\&ppid=divp85\&lpid=div18

"Art. VII. The Letters of Lord Nelson to Lady Hamilton; with a Supplement of interesting Letters, by distinguished Characters", Edinburgh Review, 1 Sep 1814, pp. 398-39813. Revisado en: http://search.ebscohost.com/login.aspx?direct=true\& $\mathrm{db}=\mathrm{h} 9 \mathrm{~h} \& \mathrm{AN}=35807577 \&$ site=eds- live\&ppid=divp136\&lpid=divl7

“Art. VIII. Memoirs of Lady Hamilton”, Monthly Review, 1 Jul 1815, pp. 295-2958. Revisado en: http://search.ebscohost.com/login.aspx?direct=true\&db=h9h\& $\mathrm{AN}=34527079 \&$ site=eds- live\&ppid=divp71\&lpid=divl8

Bermingham, Ann. "The Aesthetics of Ignorance: The Accomplished Woman in the Culture of Connoisseurship". Oxford Art Journal, vol. 16, n. ${ }^{\circ} 2$, 1993, pp. 3-20.

Burke, Peter. La fabricación de Luis XIV. Madrid, Nerea, 1995.

Colville, Quintin y Kate Williams, editores. Emma Hamilton. Seduction and Celebrity. Londres, Thames and Hudson, 2016

Constantine, David. Fields of Fire. A Life of Sir William Hamilton. Londres, Weidenfeld and Nicolson, 2001.

“Emma, Lady Hamilton”, Notes \& Queries, 3 Nov 1860, pp. 343-3432. Revisado en: 
Hellman, Jesse. "Lady Hamilton, Nelson's Enchantress, and the Creation of Pygmalion". SHAW: The Journal of Bernard Shaw Studies, vol. 35, n. ${ }^{\circ}$ 2, 2015, pp. 213-237. “Illustrations", Ladies' Monthly Museum, 1 Mayo 1815, pp. 246-2465. Revisado en: http://search.ebscohost.com/login.aspx?direct=true\&db=h9h\&AN=3870695 6\&site=eds- live\&ppid=divp2\&lpid=divl1

"Intrigues of Lady Hamilton at the Court of Naples", Analectic Magazine, 1 Ago 1813, pp. 153-1534. Revisado en: http://search.ebscohost.com/login.aspx?direct=tr $\mathrm{ue} \& \mathrm{db}=\mathrm{h} 9 \mathrm{~h} \& \mathrm{AN}=35679571 \&$ site=eds- live\&ppid=divp0067\&lpid=divl010

Jenkins, Ian y Kim Sloan. Vases and Volcanoes. Sir William Hamilton and his collection. Londres, The British Museum Press, 1996.

Jenkyns, Richard. “Eruptions”. The New Republic, 7 sep 1992, pp. 46-49.

"Lady Hamilton", Blackwood's Edinburgh Magazine, 1 Abr 1860, pp. 417-41713. Revisado en: http://search.ebscohost.com/login.aspx?direct=true\&db=h9k\&AN $=57290311 \&$ site $=$ eds- live \&ppid $=\operatorname{divp} 21 \& l$ pid $=\operatorname{divl} 2$

"Lady Hamilton", Boston Olive Branch, 26 Sep 1857, pp. 4-40. Revisado en: http:// search.ebscohost.com/login.aspx?direct $=$ true \&db=h9k\&AN=66540919\&site =eds- live\&ppid=divp4\&lpid= $\operatorname{div} 148$

"Lady Hamilton”, Boston Weekly Magazine, 29 Mar 1817, pp. 98-982. Revisado en: http://search.ebscohost.com/login.aspx?direct=true\&db=h9h\&AN=3579964 $1 \&$ site $=$ eds- live\&ppid=divp0001\&lpid $=$ divl002

"Lord Nelson and Lady Hamilton", Rural Repository, 22 Dic 1849, pp. 43-434. Revisado en: http://search.ebscohost.com/login.aspx?direct=true\&db=h9j\&AN=44758 $824 \&$ site=eds- live\&ppid=divp3\&lpid=divl2

Maierhofer, Waltraud. “Goethe on Emma Hamilton's 'Attitudes': Can Classicist Art be Fun?". Goethe Yearbook, vol. 9, 1999, pp. 222-252.

Mendelsohn, Daniel. “The Collector”. The New Republic, 15 abr 2009, https://newrepublic.com/article/62320/the-collector.

Nolta, David D. “The Body of the Collector and the Collected Body in William Hamilton's Naples". Eighteenth-Century Studies, vol. 31, n. ${ }^{\circ}$ 1, 1997, pp. 108-114.

"Obituary”, Analectic Magazine, 1 Ago 1815, 175-1752. Revisado en: http://search. ebscohost.com/login.aspx?direct=true \&db=h9h\&AN=37005966\&site=edslive\&ppid=divp0087\&lpid= $=\operatorname{div} 1015$

Olster, Stacey Michele. "Remakes, Outtakes, and Updates in Susan Sontag's The Volcano Lover". Modern Fiction Studies, vol. 41, n. ${ }^{\circ}$ 1, 1995, pp. 117-139.

Rauser, Amelia. "Living Statues and Neoclassical Dress in late Eighteenth Century Naples". Art History, vol. 38, n. ${ }^{\circ}$ 3, 2015, pp. 462-487.

Recca, Cinzia. "Amistades y estrategias políticas: Lady Hamilton en la Corte de Nápoles". Investigaciones Históricas. Época Moderna y Contemporánea, 37, 2017, pp. 329-354.

Sin título, Euterpeiad or, Musical Intelligencer, \& Ladies' Gazette, 29 Sep 1821, p. 110. Revisado en: http://search.ebscohost.com.ezproxy.bgc.bard.edu:2048/login. aspx?direct=true\&db=h9i\&AN=544 16757\&site=eds-live\&ppid=divp6 
Sin título, Spirit of The Times, 10 Nov 1849, pp. 448. Revisado en: http://search.ebscohost.com.ezproxy.bgc.bard.edu:2048/login.aspx?direct $=$ true $\& d b=h 9 j \& A N=523$ $58904 \&$ site $=$ eds-live\&ppid=divp 4

Sleep, Mark C. W., "Sir William Hamilton (1730-1803). His Work and Influence in Geology”. Annals of Science, vol. 25, 1969, pp. 319-338.

Sontag, Susan. El amante del volcán. Traducido por Marta Pessarrodona, Barcelona, Suma de Letras, 2001.

"The Letters of Lord Nelson, to Lady Hamilton; with a Supplement of Interesting Letters, by distinguished Personages", Analectic Magazine, 1 Dec 1814, pp. 4524526. Revisado en: http://search.ebscohost.com/login.aspx?direct $=$ true\& $\mathrm{db}=\mathrm{h}$ 9h\&AN=36053131\&site=eds- live\&ppid=divp0012\&lpid=divl003 